\title{
A population study of adult onset limb-girdle muscular dystrophy
}

\author{
J R W YATES* AND A E H EMERY \\ From the Medical School, University of Edinburgh, Teviot Place, Edinburgh EH8 9AG.
}

SUMMARY Complete ascertainment of adult onset limb-girdle muscular dystrophy in the Lothian Region of Scotland was attempted. Ten index cases were identified giving a prevalence of $1 \cdot 3$ per $100000(0.9$ per 100000 for cases where the diagnosis of muscular dystrophy was supported by both electromyographic and muscle biopsy findings). In these 10 sibships there had been 11 affected subjects, significantly less than the 16.5 cases expected for autosomal recessive inheritance. Excluding cases suspected of being Becker muscular dystrophy, the prevalence was 0.7 per $100000(0.3$ per 100000 for proven cases of muscular dystrophy) and there remained a significant difference between the number of cases observed (5) and the number expected (9.1) for autosomal recessive inheritance.

The prevalence of limb-girdle muscular dystrophy with onset in adult life has apparently declined over the past 30 years, as would be expected with the recognition of other conditions which cause the same pattern of weakness, making this a relatively rare disorder which should only be considered when other diagnoses have been excluded. The possibility that some cases diagnosed as limb-girdle muscular dystrophy may have had Becker muscular dystrophy emphasises the urgent need for a greater understanding of the biochemical basis of these conditions so that such diagnostic and genetic counselling dilemmas can be resolved.

Walton and Nattrass ${ }^{1}$ introduced the term limbgirdle muscular dystrophy in 1954 as part of a classification of the muscular dystrophies which gained widespread acceptance and did much to resolve the confusion up to that time. The cardinal features were:

(a) onset of shoulder or pelvic girdle weakness, usually in the second or third decade but sometimes in middle age;

(b) absence of facial weakness;

(c) a slowly progressive course with spread to all limbs and severe disability in most cases within 20 years;

(d) autosomal recessive inheritance.

Over the following 30 years it has become clear that numerous inherited and acquired disorders can produce a similar clinical picture, including nemaline myopathy, central core disease, thyrotoxic and other endocrine myopathies, the various scapuloperoneal syndromes, chronic polymyositis, man-

*Present address: Duncan Guthrie Institute of Medical Genetics, University of Glasgow, Yorkhill, Glasgow G3 8SJ.

Received for publication 3 April 1984

Accepted for publication 12 September 1984. ifesting female carriers of $\mathrm{X}$ linked Duchenne muscular dystrophy, sporadic cases of Becker muscular dystrophy, and, above all, spinal muscular atrophy. It is probable that a significant proportion of cases suspected of having limb-girdle muscular dystrophy in the past will have had one of these other disorders. ${ }^{2}$ It is not known to what extent this has reduced the apparent prevalence of limb-girdle muscular dystrophy. In children there is an autosomal recessive limb-girdle muscular dystrophy affecting the pelvic girdle and this may sometimes present in early adult life. Some authorities are now doubtful about the existence of a separate autosomal recessive lower limb-girdle muscular dystrophy of adult onset. ${ }^{2}$ In order to investigate this further we have studied cases of limb-girdle muscular dystrophy of adult onset in the Lothian Region of Scotland.

\section{Methods}

We attempted complete ascertainment of cases diagnosed as 'limb-girdle muscular dystrophy' with onset at 18 years of age or later and resident in the Lothian Region of Scotland on 30 June 1979. 
Patients previously referred to the Edinburgh University Department of Human Genetics were identified from a computerised diagnostic register. Hospital colleagues likely to encounter patients with muscular dystrophy were asked to notify cases to us. The consultant neurologists in the Lothian Region granted us access to their diagnostic indexes of inpatients and outpatients seen since 1968. Data from the Hospital Activity Analysis were used to identify residents of the Lothian Region who had been coded as having muscular dystrophy following an admission to any hospital in Scotland since 1969. Hospital case notes were reviewed with the permission of the consultant concerned in order to establish the type of muscular dystrophy and the age at onset. If the diagnosis was in doubt, the patients were seen and reassessed. A search through the muscle biopsy reports of one Edinburgh hospital failed to reveal any patients who had not already been ascertained by these other methods and a similar search through the records of the two remaining pathology departments in the Region was not thought worthwhile.

Patients were invited to participate in the study with the agreement of both the hospital consultant concerned and their general practitioner. Most patients were seen on more than one occasion. A detailed history was taken, including a family pedigree, and the patients were carefully examined. The results of past investigations were scrutinised and if a muscle biopsy had been done the histology was reviewed. Informed consent was obtained for all further investigations carried out. If there was any possibility that a relative was affected, they were also seen and carefully examined. All available first degree female relatives of cases with features suggestive of Becker muscular dystrophy were examined and blood taken for estimation of serum creatine kinase.

\section{Results}

Ten index cases were identified as having 'limbgirdle muscular dystrophy' of adult onset who were resident in the Lothian region of Scotland on 30 June 1979. They came from nine families containing a single affected subject and one family in which there had been two affected brothers. There was a striking excess of males, with only one female among these 11 cases. There was no parental consanguinity and no history of neuromuscular disease in the parents or more distant relatives, with the possible exception of family $\mathrm{H}$ where the maternal grandfather of the index case had been confined to a wheelchair for most of his adult life. The family attributed this to 'dropsy'.

\section{CLINICAL FINDINGS}

All the affected subjects had normal early motor development and were healthy and active in childhood. The age at onset, course of the disease, and age at examination are given in table 1. Clinical findings are summarised in table 2 . None of the patients had fasciculation and except where stated none had facial weakness. Results of serum creatine kinase estimation, electromyography, and muscle biopsy are summarised in table 3 . Unless stated otherwise, electromyography and muscle histology were entirely in keeping with a diagnosis of muscular dystrophy, and other investigations such as routine haematology and biochemistry, thyroid function, chest $x$-ray, and ECG were normal. Clinical findings and results of serum creatine kinase estimation in available first degree female relatives

TABLE 1 Age at onset, course of disease, and age at examination in affected subjects.

\begin{tabular}{|c|c|c|c|c|c|c|c|}
\hline \multirow[t]{2}{*}{ Family } & \multirow[t]{2}{*}{ Subject $^{*}$} & \multirow[t]{2}{*}{ Sex } & \multicolumn{4}{|l|}{ Age $(y)$} & \multirow[t]{2}{*}{ Mobility } \\
\hline & & & $\begin{array}{l}\text { Onset of } \\
\text { symptoms }\end{array}$ & $\begin{array}{l}\text { Symptoms in } \\
\text { upper limbs }\end{array}$ & $\begin{array}{l}\text { Symptoms in } \\
\text { lower limbs }\end{array}$ & $\begin{array}{l}\text { At } \\
\text { examination }\end{array}$ & \\
\hline A & $J S$ & Male & 31 & At onset & None & 35 & Ambulant \\
\hline B & $W B$ & Male & 29 & At onset & 49 & 55 & Ambulant \\
\hline $\mathrm{C}$ & $J L$ & Male & 26 & At onset & 36 & 69 & Ambulant \\
\hline D & $C C$ & Male & 19 & 21 & At onset & 57 & $\begin{array}{l}\text { Confined to wheelchair since } \\
41 \text { years of age }\end{array}$ \\
\hline $\mathbf{E}$ & $A M$ & Female & 28 & 38 & At onset & 44 & Ambulant \\
\hline $\mathrm{F}$ & $P D$ & Male & 19 & 27 & At onset & 27 & Ambulant \\
\hline G & $G N$ & Male & 18 & None & At onset & 23 & Ambulant \\
\hline $\mathbf{H}$ & $J B$ & Male & 21 & 38 & At onset & 56 & Ambulant \\
\hline \multirow[t]{2}{*}{ I } & $T W$ & Brothers & 34 & 36 & At onset & 54 & $\begin{array}{l}\text { Confined to wheelchair since } \\
44 \text { years of age }\end{array}$ \\
\hline & FW & & 30 & 36 & At onset & $\begin{array}{l}\text { Not } \\
\quad \text { examined }\end{array}$ & $\begin{array}{l}\text { Ambulant at } 42 \text { ycars of age } \\
\text { when killed in an accident }\end{array}$ \\
\hline J & $E O$ & Male & 45 & 57 & At onset & 60) & Ambulant \\
\hline
\end{tabular}

${ }^{*}$ Index cases in italics. 
TABLE 2 Clinical features in affected subjects.

\begin{tabular}{|c|c|c|c|c|c|c|}
\hline \multirow[t]{2}{*}{ Subject } & \multicolumn{3}{|c|}{ Pattern of muscle involvement } & \multirow{2}{*}{$\begin{array}{l}\text { Winging } \\
\text { of scapulae }\end{array}$} & \multirow{2}{*}{$\begin{array}{l}\text { Calf } \\
\text { hypertrophy }\end{array}$} & \multirow[t]{2}{*}{ Other } \\
\hline & Mildly affected & Intermediate & Most affected & & & \\
\hline JS & $\underset{\text { inf }}{\text { Trap (up), delt, sup, }}$ & Rt stern, It bi, tri & $\begin{array}{l}\text { Trap (low), rhom, serr, } \\
\text { lat, pect (clav+sc), rt bi }\end{array}$ & +++ & - & $\begin{array}{l}\text { Paroxysmal } \\
\text { tachycardia* }\end{array}$ \\
\hline WB & Delt. Hip flx & Sho & $\mathrm{Bi}$, tri & +++ & + & $\begin{array}{l}\text { Contractures at } \\
\text { shoulder joints }\end{array}$ \\
\hline JL & $\begin{array}{l}\text { Trap (up), delt, sup, } \\
\text { inf, brach. Ham, calf }\end{array}$ & $\begin{array}{l}\text { Trap (low), rhom, serr, } \\
\text { lat, pect (clav+sc), } \\
\text { lt bi. Pelv, peron }\end{array}$ & Rt bi, tri. Quad & ++ & - & $\begin{array}{l}\text { Contractures at } \\
\text { shoulder joints }\end{array}$ \\
\hline $\mathrm{CC}$ & $\begin{array}{l}\text { Stern, trap (up), brach, } \\
\text { dist up }\end{array}$ & $\begin{array}{l}\text { Serr, delt, sup. Calf, } \\
\text { peron }\end{array}$ & $\begin{array}{l}\text { Trap (low), rhom, lat, } \\
\text { pect (clav }+ \text { sc), inf, bi, } \\
\text { tri. Pelv. ham. quad }\end{array}$ & + & - & $\begin{array}{l}\text { Contractures at } \\
\text { shoulder, elbow, } \\
\text { hip, and ankle joints }\end{array}$ \\
\hline AM & $\begin{array}{l}\text { Stern, trap (up), } \\
\text { dist up. Calf, peron }\end{array}$ & $\begin{array}{l}\text { Rhom, serr, lat, pect } \\
\text { (clav+sc), delt, sup, } \\
\text { inf, tri, brach. Pelv, } \\
\text { It ham }\end{array}$ & Bi. Rt ham, quad & - & - & $\begin{array}{l}\text { Mild mental } \\
\text { retardation }\end{array}$ \\
\hline PD & Peron & $\begin{array}{l}\text { Lat, pect (sc). Hip add, } \\
\text { hip abd, ham }\end{array}$ & 'Hip flx, hip ext, quad & - & +++ & \\
\hline GN & Rhom, delt, sup. Ham & $\begin{array}{l}\text { Serr, lat, pect (clav). } \\
\text { Quad }\end{array}$ & Pect (sc). Pelv & + & +++ & \\
\hline JB & Serr, tri. Calf & $\begin{array}{l}\text { Delt, sup, bi, brach. } \\
\text { Ham, peron }\end{array}$ & $\begin{array}{l}\text { Rhom, lat, pect (sc), } \\
\text { inf. Pelv, quad }\end{array}$ & + & +++ & $\begin{array}{l}\text { Right bundle } \\
\text { branch block }\end{array}$ \\
\hline TW & Orb. Dist up. & $\begin{array}{l}\text { Stern, trap, rhom, serr, } \\
\text { pect (clav), delt, sup, } \\
\text { inf, bi, tri }\end{array}$ & $\begin{array}{l}\text { Lat, pect (sc), brach. } \\
\text { Pelv, ham, quad, calf, } \\
\text { peron }\end{array}$ & + & - & Ichthyosis \\
\hline FW & \multicolumn{3}{|c|}{$\begin{array}{l}\text { According to the hospital records had wasting of quadriceps and marked } \\
\text { weakness of flexion, extension, and adduction at the hips and flexion and } \\
\text { extension at the knees. Also some proximal weakness in upper limbs }\end{array}$} & $\begin{array}{l}\text { Not } \\
\text { stated }\end{array}$ & Prominent & $\begin{array}{l}\text { Ichthyosis and } \\
\text { neurofibromatosis }\end{array}$ \\
\hline EO & $\begin{array}{l}\text { Lat, pect }(\text { clav }+s c) \\
\text { delt, sup }\end{array}$ & Tri. Pelv & Quad & - & ++ & \\
\hline
\end{tabular}

*Occasional brief paroxysmal tachycardia, sinus bradycardia on ECG, normal chest $x$-ray, and echocardiography.

$\mathrm{Lt}=$ left. $\mathrm{Rt}=$ right. $\mathrm{Bi}=$ biceps. Brach=brachioradialis. Calf $=$ calf muscles. Delt $=$ deltoid. Dist up=distal upper limb muscles. Ham=hamstrings. Hip abd=hip abductors. Hip add=hip adductors. Hip ext=hip extensors. Hip flx=hip flexors. Inf=infraspinatus. Lat=latissimus dorsi. Orb=orbicularis oculi. Pect $($ clav $/ \mathbf{s c})=$ pectoralis major (clavicular/sternocostal fibres). Pelv=pelvic girdle muscles. Peron=peroneal muscles. Quad=quadriceps. . Rhom $=$ rhomboids. Serr $=$ serratus anterior. Sho $=$ shoulder girdle muscles. Stern=sternomastoid. Sup $=$ supraspinatus. Trap (up/low) $=$ trapezius (upper/lower fibres). Tri $=$ triceps. $+=$ mild. $++=$ moderate. $+++=$ severe.

TABLE 3 Results of serum creatine kinase estimation, electromyography, and muscle biopsy in affected subjects.

\begin{tabular}{|c|c|c|c|c|}
\hline \multirow[t]{2}{*}{ Subject } & \multicolumn{2}{|c|}{ Serum creatine kinase } & \multicolumn{2}{|c|}{ Diagnostic conclusion } \\
\hline & This study* (IUIl) & Previous estimationst & Electromyography & Muscle biopsy \\
\hline WB & - & $\mathbf{N}$ & Myopathy & - \\
\hline JL & 51 & - & - & - \\
\hline $\mathrm{CC}$ & 21 & $\mathbf{N}$ & Myopathy & - \\
\hline AM & - & +++ & Myopathy & Myopathy \\
\hline GN & 1800 & ++ & Mixed picture & Myopathy \\
\hline JB & 400 & ++ & Myopathy & Myopathy \\
\hline TW & 200 & +++ & Myopathy & - \\
\hline FW & - & +++ & - & Myopathy§ \\
\hline EO & 1220 & ++ & Myopathy & Myopathy \\
\hline
\end{tabular}

*Department of Human Genetics, University of Edinburgh.

Normal range: males $0-150$ IU/l, females $0-86$ IU/l.

+ Various laboratories.

Normal $=N$. Raised $=+$. Greater than 5 times the upper limit of the normal range $=++$.

Greater than 10 times the upper limit of the normal range $=+++$

$\ddagger$ Electromyography revealed a clear myopathic picture in the majority of muscles examined, with motor unit action potentials of reduced amplitude and duration, increased polyphasia, and a full recruitment pattern on maximum exertion. In the right biceps, the weakest muscle clinically, some large action potentials were recorded and a full interference pattern could not be obtained. Muscle histology showed for the most part florid myopathic changes. None of the frozen sections showed evidence of denervation but in the paraffin sections the possibility of fibre group atrophy could not be ruled out. Electromyographic and muscle biopsy findings were therefore thought to favour muscular dystrophy but neurogenic atrophy could not be entirely excluded.

$\S$ At necropsy the dystrophic process could be observed over a wide range of severity in the several muscles studied. Histology of the spinal cord and nerve roots was normal. 
of suspected cases of Becker muscular dystrophy are given in table 4.

PREVALENCE

The Lothian Region comprises the city of Edinburgh and the surrounding districts of East Lothian, Midlothian, and West Lothian. On 30 June 1979, the estimated population was $750728.3^{3}$ Ten cases diagnosed as limb-girdle muscular dystrophy with adult onset and resident in Lothian on this date were ascertained, giving a prevalence of 1.3 per 100000 $(0.9$ per 100000 for cases where the diagnosis of muscular dystrophy was supported by electromyographic and muscle biopsy findings). Five cases (PD, GD, JB, TW, and EO) had features suggestive of Becker muscular dystrophy, as discussed below, and excluding these the prevalence was 0.7 per 100000 $(0.3$ per 100000 for proven cases of muscular dystrophy). The prevalence data are summarised in table 5. All but one of the probands were ascertained more than once and the mean number of ascertainments was $2 \cdot 2$. The only affected subject not ascertained as an index case (FW, family I) had died in 1966. Different ascertainments of the same proband were not necessarily independent. For example, referral to a consultant might be followed by admission to hospital, muscle biopsy, and referral for genetic counselling, each event subsequently leading to another ascertainment of the case. This does not constitute a well defined sampling scheme and we cannot be certain about the completeness of ascertainment.

\section{SEGREGATION ANALYSIS}

Details of the incidence of the disease in the ten families are given in table 6 . Five subjects who had not reached the age at which symptoms first appeared in affected sibs have been omitted. There were nine families containing a single case and one family with two affected brothers, making a total of 11 affected persons out of 48 sibs. This is significantly less than the 16.5 cases expected for autosomal recessive inheritance (table 7), even on the assumption that ascertainment was complete and families with a single affected person were fully represented. ${ }^{+}$If the five cases with features suggestive of Becker muscular dystrophy are excluded, the difference is still significant (number expected $=9 \cdot 1$; number observed $=5 ; \mathrm{p}<0 \cdot 04)$.

TABLE 4 Clinical findings and serum creatine kinase in first degree female relatives of suspected cases of Becker muscular dystrophy.

\begin{tabular}{|c|c|c|c|}
\hline Family & Subject & Examination & $\begin{array}{l}\text { Serum creatine kinase } \\
(I U l)\end{array}$ \\
\hline $\mathrm{F}$ & BD. daughter of PD & Normal & 82 \\
\hline G & $\mathrm{MN}$, mother of GN & Normal & 54 \\
\hline $\mathrm{H}$ & DG, daughter of $\mathrm{JB}$ & Normal & 25 \\
\hline I & $\mathrm{CW}$. daughter of $\mathrm{FW}$ & $\begin{array}{l}\text { Unstable patellae. slight weakness of } \\
\text { left quadriceps. mild left pes cavus. } \\
\text { Neurofibromatosis }\end{array}$ & 43 \\
\hline
\end{tabular}

*Department of Human Genetics, University of Edinburgh. Normal range in females: (1-86 IU/l.

TABLE 5 Prevalence of limb-girdle muscular dystrophy in Lothian Region*.

\begin{tabular}{|c|c|c|c|c|}
\hline \multirow[t]{2}{*}{$\begin{array}{l}\text { Predominant } \\
\text { weakness }\end{array}$} & \multicolumn{2}{|l|}{ All cases } & \multicolumn{2}{|c|}{$\begin{array}{l}\text { Proven cases of } \\
\text { muscular dystrophy only }\end{array}$} \\
\hline & No of cases & $\begin{array}{l}\text { Prevalence } \\
\text { per } 1(0)(0) 0\end{array}$ & No of cases & $\begin{array}{l}\text { Prevalence } \\
\text { per } 100000\end{array}$ \\
\hline Upper limb & 3 & 0.4 & 1 & 0.1 \\
\hline Lower limb & 7 & 0.9 & 6 & 0.8 \\
\hline \multicolumn{5}{|c|}{$\begin{array}{l}\text { Excluding possible } \\
\text { cases of Becker } \\
\text { muscular dystrophy }\end{array}$} \\
\hline Lower limb & 2 & $0 \cdot 3$ & 1 & 0.1 \\
\hline Total & 5 & 0.7 & 2 & 0.3 \\
\hline
\end{tabular}

*Estimated population of Iothian Region on 30 June 1979 was $750728 .^{4}$ 
TABLE 6 Structure of sibships containing affected persons.

\begin{tabular}{|c|c|c|c|c|c|c|}
\hline \multirow[t]{2}{*}{ Family } & \multicolumn{3}{|c|}{ No of affected sibs (including proband) } & \multicolumn{3}{|c|}{ No of unaffected sibs* } \\
\hline & Male & Female & Total & Male & Female & Total \\
\hline B & 1 & 0 & 1 & 3 & 4 & 7 \\
\hline $\mathrm{C}$ & 1 & 0 & 1 & 6 & 3 & 9 \\
\hline D & 1 & 0 & 1 & 0 & 0 & 0 \\
\hline $\mathrm{E}$ & 0 & 1 & 1 & 2 & 2 & 4 \\
\hline $\mathrm{G}$ & 1 & 0 & 1 & 0 & 0 & 0 \\
\hline $\mathrm{H}$ & 1 & 0 & 1 & 0 & 1 & 1 \\
\hline I & 2 & 0 & 2 & 4 & 4 & 8 \\
\hline $\mathbf{J}$ & 1 & 0 & 1 & 0 & 1 & 1 \\
\hline Total & 10 & 1 & 11 & 18 & 19 & 37 \\
\hline
\end{tabular}

${ }^{*}$ Subjects who had not reached the age at which definite symptoms appeared in affected sibs have been omitted.

TABLE 7 Comparison between the observed number of cases and the expected number assuming autosomal recessive inheritance and complete ascertainment. ${ }^{5}$

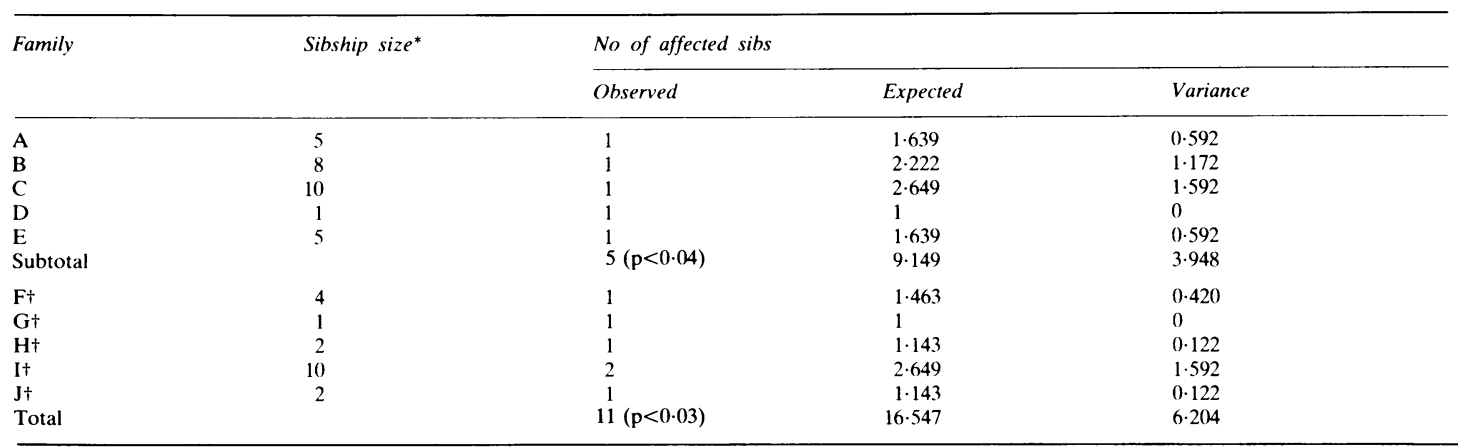

*Subjects who had not reached the age at which symptoms first appeared in affected sibs have been omitted tFamilies containing possible cases of Becker muscular dystrophy.

\section{Discussion}

The patients in this study show much diversity in their clinical features, particularly with regard to age at onset, pattern of muscle involvement, and course of the disease. The three cases with onset in the upper limbs have some features in common and will be discussed as a group. Patients with predominantly lower limb weakness and a pattern of muscle involvement similar to that seen in Becker muscular dystrophy form another distinct group that will be discussed below.

JS, WB, and JL all had onset of weakness in the upper limbs. Initial symptoms related to weakness of the biceps in all cases and started in young adult life. Wasting of the upper arms was noticeable at an early stage. Weakness spread to the shoulders, particularly involving the lower fibres of trapezius, rhomboids, serratus anterior, pectoralis major, and latissimus dorsi. Scapular winging was a prominent feature. Deltoids and spinati were somewhat pre- $\frac{0}{3}$ served. In the two older patients (WB and JL) progression had been very slow. Weakness had spread to the lower limbs after 10 to 20 years, initially affecting the proximal muscles, especially the hip flexors, and they were still ambulant at 55 and 69 years of age respectively. In both, contractures limiting abduction at the shoulder joint had $N$ developed later in the course of the disease. This $N$ pattern of wasting and weakness in the upper limbs $N$ is well described by the term scapulohumeral, and $\omega$ the clinical features in these three cases resemble the traditional juvenile type of muscular dystrophy first $\stackrel{0}{\complement}$ described by Erb. ${ }^{5}$ Spinal muscular atrophy can produce an identical clinical picture and this diagnosis could not be excluded in JL or WB, who had not had muscle biopsies and declined further investigation. In JS the presence of some asymmetry of $\frac{?}{\mathbb{D}}$ muscle involvement also pointed to this diagnosis, 응 but muscle histology and electrophysiology were 
thought to favour muscular dystrophy, although neurogenic atrophy could not be completely excluded. Weakness and wasting of the sternomastoids in JS was also present in two cases reported by Walton and Nattrass. ${ }^{1}$

The majority of cases with onset in the pelvic girdle had calf hypertrophy and other features characteristic of Becker muscular dystrophy. ${ }^{26}$ Thus, in the shoulder girdle, weakness and wasting was most marked in the sternocostal fibres of pectoralis major and in latissimus dorsi. Involvement of biceps and triceps tended to lag behind the shoulder girdle muscles, and in two cases there was striking weakness of brachioradialis. Scapular winging was mild or absent. In the lower limbs weakness and wasting particularly affected hip flexion and extension and knee extension, hamstrings being relatively preserved. Values of serum creatine kinase were high.

PD and GN had this typical Becker phenotype. JB had several of these features. Furthermore, his maternal grandfather was confined to a wheelchair for much of his adult life. The family attributed this to 'dropsy', but the possibility of X linked muscular dystrophy cannot be excluded. In all three cases, the diagnosis of muscular dystrophy was confirmed by electromyography and muscle biopsy.

TW had extensive weakness of all the scapulohumeral muscles, but the costal fibres of pectoralis major, latissimus dorsi, and brachioradialis were noticeably more severely affected. Lower limb muscles were almost completely paralysed and at the time of our examination he had been confined to a wheelchair for 10 years. He did not have calf hypertrophy and had no recollection of having had prominent calves in the past. At presentation to a neurologist two years after onset of symptoms, his calves were said to show wasting. In contrast, it is clear from the hospital records that calf hypertrophy was present in his brother, FW, in whom a diagnosis of pseudohypertrophic muscular dystrophy had been made some time previously. They both had very high levels of serum creatine kinase. FW had biopsy findings confirming muscular dystrophy. Furthermore, at necropsy following a fatal accident, histology in several of his muscles showed the dystrophic process at varying stages of advancement and histological examination of the spinal cord and nerve roots was normal, ruling out spinal muscular atrophy. If Becker muscular dystrophy is accepted as the most probable diagnosis in FW, it is likely that his brother TW has the same condition, although the absence of calf hypertrophy would be an unusual feature. $^{6}$ The pes cavus, mild quadriceps weakness, and patella instability in his daughter, CW, could be interpreted as minor manifestations of the condition in an obligate heterozygote, although if this is the correct explanation it is surprising that her serum creatine kinase was normal. A minority of carriers of the Duchenne muscular dystrophy gene exhibit some degree of weakness, ${ }^{7}$ but this appears to be rare for Becker muscular dystrophy carriers. ${ }^{8}$

EO was also thought to have calf hypertrophy, but less striking than in the cases mentioned above. In the absence of normal values for calf size this is inevitably a somewhat subjective assessment and extensive wasting of the quadriceps can give a false impression of calf enlargement. His pattern of muscle involvement was also compatible with a diagnosis of Becker muscular dystrophy and the serum creatine kinase was ten times the upper limit of the normal range. Electromyography and muscle biopsy were entirely consistent with a diagnosis of muscular dystrophy. Onset of symptoms at 45 years of age would be unusual for Becker muscular dystrophy but does not rule out this diagnosis. ${ }^{2}$

Of the ten index cases in this study, nine were male and this striking excess of males provides further support for the suggestion that some or all of the five patients discussed above were cases of Becker rather than limb-girdle muscular dystrophy. Further evidence for this might have come from the measurement of serum creatine kinase in their daughters, since $60 \%$ of obligate carriers of Becker muscular dystrophy have values above the normal range. ${ }^{9}$ However, none of their daughters was found to have a level above the normal 95th centile.

Of the two remaining patients with onset in the pelvic girdle, $\mathrm{CC}$ had a pattern of wasting and weakness in the upper limbs resembling that seen in scapulohumeral muscular dystrophy, but without marked winging of the scapulae. He had never had calf hypertrophy and his serum creatine kinase was normal. Electromyography suggested a myopathy but he declined muscle biopsy so that spinal muscular atrophy and other diagnoses could not be excluded. AM, the only female patient in this study, also had a scapulohumeral pattern of weakness in the upper limbs, but no winging of the scapulae. In the lower limbs she had predominantly proximal weakness, particularly affecting the quadriceps muscles. Electromyography and muscle biopsy both supported a diagnosis of muscular dystrophy. Her serum creatine kinase was high, being raised more than ten-fold. Onset at the age of 28 years would be unusually late for autosomal recessive muscular dystrophy of childhood, but not impossible since cases with onset as late as 27 years of age have been reported. ${ }^{10}$ However, in that and other studies, levels of serum creatine kinase greater than ten times the upper limit of the normal range have only been observed in childhood and adolescence. The 
very high enzyme level found in this patient raises the possibility that she might be a manifesting carrier of the Duchenne gene, as suggested by Moser and Emery. ${ }^{7}$

Previous studies of the frequency of limb-girdle muscular dystrophy have not distinguished adult from childhood onset, and have obtained values ranging from 0.9 to 3.3 per 100000 for the prevalence, making no adjustment for incomplete ascertainment. ${ }^{11} 12$ The study by Walton ${ }^{11}$ includes information about the age at onset of symptoms from which the prevalence of cases with adult onset can be estimated to be 0.6 per 100000 . With one possible exception, none of their patients had calf hypertrophy, so that it is unlikely that any cases of Becker muscular dystrophy were included, being allocated instead to their Duchenne muscular dystrophy group. Excluding cases with a Becker phenotype, the value of 0.7 per 100000 for the prevalence in this region is little different from that found in north-east England almost 30 years ago. However, the prevalence in this region is lower if only proven cases of muscular dystrophy are included, being reduced to $0 \cdot 3$ per 100000 . Furthermore, the prevalence for all ages in the earlier report is the lowest value found in any study to date, suggesting that either this is an area with a particularly low frequency of this condition or, more likely, that ascertainment was incomplete. It is therefore probable that the prevalence we have observed does represent a decline, as would be expected with the recognition nowadays of numerous conditions causing the same pattern of weakness. Indeed, during the course of this study we came across patients with spinal muscular atrophy (four cases), as well as single cases of carnitine deficiency and thyrotoxic myopathy who might well have been misdiagnosed as limb-girdle muscular dystrophy in the past.

In the original publications on limb-girdle muscular dystrophy ${ }^{111}$ the evidence for autosomal recessive inheritance was unconvincing. The proband was the only affected subject in all but two of the 16 families in which the index case was not an only child. In one of these families a brother and sister were affected from a sibship of five, and in the remaining family two brothers were affected from a sibship of six and there was little doubt that their mother had also been affected. Using this and other data Morton and Chung ${ }^{13}$ concluded that only $60 \%$ of cases could be the result of autosomal recessive inheritance and that the remaining $40 \%$ were phenocopies of unknown aetiology. In the present study the ten families contained only 11 affected subjects, significantly fewer than expected on the basis of autosomal recessive inheritance, even if complete ascertainment is assumed. Moreover, it is possible that in the family containing two affected brothers, the diagnosis was Becker muscular dystrophy. Excluding the five families where this diagnosis was thought likely, the number of affected subjects was still significantly less than predicted for an autosomal recessive mode of transmission. The evidence for autosomal recessive inheritance of limb-girdle muscular dystrophy might have been strengthened by the recognition of an increasing number of disorders causing proximal weakness which in the past would have introduced heterogeneity into the material used for segregation analysis. This has not been found and it probably remains true that a substantial proportion of cases are phenocopies of unknown aetiology.

Adult onset limb-girdle muscular dystrophy appears to be a relatively rare condition and this diagnosis should only be entertained when other causes of such weakness have been excluded. Several of the patients in this study with a diagnosis of limb-girdle muscular dystrophy had features of Becker muscular dystrophy. It has been suggested that isolated cases with an unequivocal Becker phenotype should be counselled on the basis of $\mathrm{X}$ linked recessive inheritance. ${ }^{2}$ For equivocal cases, the situation is more difficult, but it would probably be unwise to counsel them on the basis of autosomal recessive inheritance and reassure their daughters that there was little risk to their offspring. There is an urgent need for a greater understanding of the biochemical basis of these disorders so that such diagnostic and genetic counselling dilemmas can be resolved.

This work was supported by grants from the Muscular Dystrophy Group of Great Britain and the Elf Oil Company to AEHE. We are grateful to the several clinicians who granted us access to their patients. We would also like to thank the patients and their families for cooperating with this study.

\footnotetext{
References

1 Walton JN, Nattrass FJ. On the classification, natural history and treatment of the myopathies. Brain 1954;77:169-231.

2 Walton JN, Gardner-Medwin D. Progressive muscular dystrophy and the myotonic disorders. In: Walton JN, ed. Disorders of voluntary muscle. Edinburgh: Churchill Livingstone, 1981:481524.

3 Annual Report of the Registrar General for Scotland 1979. Edinburgh: HMSO, 1981.

${ }^{4}$ Emery AEH. Methodology in medical genetics. Edinburgh: Churchill Livingstone, 1976.

${ }^{5}$ Erb WH. Uber die juvenile Form der progressiven Muskelatrophie. Dtsch Arch Klin Med 1884;34:467-519.

${ }^{6}$ Emery AEH, Skinner R. Clinical studies in benign (Becker type) X-linked muscular dystrophy. Clin Genet 1976;10:189201.

7 Moser H, Emery AEH. The manifesting carrier in Duchenne muscular dystrophy. Clin Genet 1974;5:271-84.
} , N

(n)

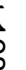

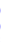


${ }^{8}$ Aguilar L, Lisker R, Ramos GG. Unusual inheritance of Becker type muscular dystrophy. J Med Genet 1978:15:116-8.

${ }^{9}$ Skinner R, Emery AEH, Anderson AJB, Foxall C. The detection of carriers of benign (Becker type) $\mathrm{X}$ linked muscular dystrophy. J Med Genet 1975;12:131-4.

${ }^{10}$ Moser H, Wiesmann U, Richterich R, Rossi E. Progressive Muskeldystrophie. VIII. Haufigkeit, Klinik und Genetik der Typen I und II. Schweiz Med Wochenschr 1966;96:169-211.

1 Walton JN. On the inheritance of muscular dystrophy. Ann Hum Genet 1955;20:1-38.
12 Monckton G, Hoskin V, Warren S. Prevalence and incidence of muscular dystrophy in Alberta, Canada. Clin Genet 1982;21:1924.

${ }^{13}$ Morton NE, Chung CS. Formal genetics of muscular dystrophy. Am J Hum Genet 1959;11:360-79.

Correspondence and requests for reprints to $\mathrm{Dr}$ J R W Yates, Duncan Guthrie Institute of Medical Genetics, Yorkhill, Glasgow G3 8SJ.

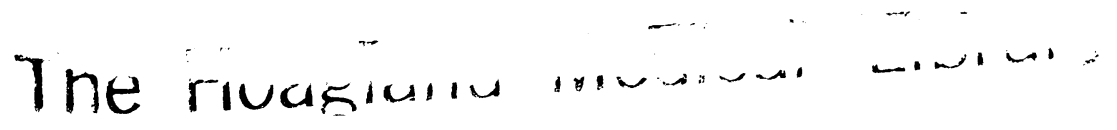

